Supporting Information

\title{
Depletion effect-mediated association of carbon nanotube- polymer composites and their application as inexpensive electrode support materials
}

Zhangjun Huang and Paul J. Dyson*

Institut des Sciences et Ingénierie Chimiques, Ecole Polytechnique Fédérale de Lausanne (EPFL), CH-1015

Lausanne, Switzerland.

Table of Contents

I) Material synthesis

II) Characterization

III) Figures S1-S5

IV) NMR dataset

V) References 


\section{Material synthesis}

Chemicals: CNTs (multi-walled, 95\%, Sigma), polystyrene (1.3, 13 and $123 \mathrm{kDa}$, Alfa Aesar), poly(vinyl chloride) ( $233 \mathrm{kDa}$, Sigma), poly(vinyl butyal) ( $\sim 85 \mathrm{kDa}$, Sigma), poly(N-vinylcarbazole) ( 90 kDa, Acros), polyacrylonitrile ( 150 kDa, Sigma), polyvinylpyrrolidone ( $\sim 29 \mathrm{kDa}$, Applichem), poly(ethylene-co-vinyl acetate) ( 40 kDa, vinyl acetate $25 \%$, Sigma), poly(vinyl alcohol) ( $27 \mathrm{kDa}$, Acros), and polyethylene glycol ( $\sim 35 \mathrm{kDa}$, Sigma) were used as received without any purification. All organic solvents were of analytical grade and Mili-Q water (18 $\mathrm{M} \Omega \mathrm{cm})$ was used.

Synthesis of the CNT-polymer composites: See section on characterization of ${ }^{1} \mathrm{H}$ NMR spectroscopy.

Synthesis of the rhodamine B-doped CNTs: CNTs (10 mg) was soaked in rhodamine B solution (200 ppm, $2 \mathrm{~mL}$ ) in a glass tube overnight. The CNTs were removed and soaked in water, the water was replaced 2 6 times every day till no obvious release of rhodamine B was observed. The rhodamine B-doped CNTs were then dried at $50{ }^{\circ} \mathrm{C}$.

Synthesis of the CNT membranes: Multi-walled CNTs ( $1 \mathrm{~g})$ were suspended in ethanol $(1 \mathrm{~L})$ with the aid of ultrasound to form slurry. The slurry $(35 \mathrm{~mL} \times 2)$ was poured into a glass petri-dish $\left(10 \mathrm{~cm}\right.$ in diameter), and the solvent evaporated to drying at $50{ }^{\circ} \mathrm{C}$. The resulting CNT membrane was carefully peeled from the petri-dish using tweezers.

Synthesis of the CNT-PVC composite membranes: PVC (100 mg) was dissolved in THF $(100 \mathrm{~mL})$ to form a clear solution. A petri-dish $(10 \mathrm{~cm}$ in diameter $)$ containing the CNT membrane (70 mg) was placed on the petri-dish, the PVC solution (30 mL) was added and stored at room temperature overnight. The PVC solution was decanted, and the CNTPVC membrane was washed with THF $(30 \mathrm{~mL})$ three times for $10 \mathrm{~min}$ then dried naturally. Water $(20 \sim 30 \mathrm{~mL})$ was poured into the petri-dish, and the CNT-PVC composite membrane was removed with a spatula. The detached CNT-PVC membrane automatically floats to the water surface.

Synthesis of the CNT-PAN composite membrane: PAN (1 g) was dissolved in DMSO $(1 \mathrm{~L})$ to form a clear solution. A petri-dish $(10 \mathrm{~cm}$ in diameter $)$ containing the CNT membrane $(70 \mathrm{mg})$ was placed on the petri-dish, the PAN solution $(30 \mathrm{~mL})$ was added and stored at room temperature overnight. The PAN solution was decanted, and the CNT-PAN 
membrane was washed with DMSO $(30 \mathrm{~mL})$, ethanol $(30 \mathrm{~mL})$ and then water $(30 \mathrm{~mL})$ for 10 min. The CNT-PAN membrane was removed with a spatula, and stored in water.

Synthesis of the CNT-PAN-Pt composite membrane electrode: $\mathrm{H}_{2} \mathrm{PtCl}_{6}(120$ $\mathrm{mg}$ ) was dissolved in $0.1 \mathrm{M} \mathrm{H}_{2} \mathrm{SO}_{4}(10 \mathrm{~mL})$ to form a clear electrolyte solution. The CNTPAN composite electrode $(8 \times 25 \mathrm{~mm})$ was half-immersed in the electrolyte and a voltage of $\mathrm{E}_{\mathrm{vs} . \mathrm{Ag} / \mathrm{AgCl}}=-0.35 \mathrm{~V}$ was applied for $10 \mathrm{~s}$, then $\mathrm{E}_{\mathrm{vs} . \mathrm{Ag} / \mathrm{AgCl}}=0 \mathrm{~V}$ was applied for another 10s. The procedure was repeat 50 times. The obtained CNT-PAN-Pt composite membrane electrode was rinsed with deionized water three times, and stored in water.

Synthesis of hydrophilic CNTs: CNTs $(0.5 \mathrm{~g})$ were added to an aqueous $30 \%$ $\mathrm{H}_{2} \mathrm{O}_{2}$ solution (50 mL) and stirred for 7 days at $60{ }^{\circ} \mathrm{C} . \mathrm{H}_{2} \mathrm{O}_{2}(5 \mathrm{~mL})$ was added to the slurry each day. The oxidized CNTs were collected by filtration, washed with deionized water, and dried overnight at $110^{\circ} \mathrm{C} .{ }^{36}$ 


\section{Characterization}

${ }^{1} \mathrm{H}$ NMR spectra were recorded on a Bruker AV-Neo 500 instrument using NMR tubes with screw-caps. $0.7-1.9 \mathrm{mg}$ of the appropriate polymer was dissolved in ca. 0.5 $\mathrm{mL}$ of the required deuterated solvent (refer to the Table 1 in the main manuscript). $0.5-$ $1.8 \mathrm{mg}$ of corresponding calibrants, i.e. imidazole, tri-tert-butylbenzene or lindane, were dissolved in the polymer solutions. For calibration, ${ }^{1} \mathrm{H}$ NMR spectra of each polymer solution at the desired temperature were recorded. For the equilibrium study, CNTs (1.8 $2.3 \mathrm{mg}$ ) were deposited at the bottom of the NMR tube containing the appropriate polymer solution and ${ }^{1} \mathrm{H}$ NMR spectra were recorded at the desired temperature until equilibrium was reached. The temperature range for dichloromethane solutions is $15-35^{\circ} \mathrm{C}$, and for the all other solutions is $25-50^{\circ} \mathrm{C}, 5^{\circ} \mathrm{C}$ interval. To calculate the corresponding enthalpy $(\Delta \mathrm{H})$ and entropy $(\Delta \mathrm{S})$ of the CNT-polymer association process, the ${ }^{1} \mathrm{H}$ NMR spectra were processed with the relation $\mathrm{R} \ln \left(\mathrm{K}_{\mathrm{eq}}\right)=-\Delta \mathrm{H} / \mathrm{T}+\Delta \mathrm{S}$, where $\mathrm{R}$ is the gas constant, $\mathrm{K}_{\mathrm{eq}}$ is the equilibrium constant that equals to the ratio of polymers dissolving in solution and associating on the CNTs, T is temperature.

The ${ }^{1} \mathrm{H}$ and ${ }^{13} \mathrm{C}$ NMR spectra for the $0.5 \mathrm{M} \mathrm{H}_{2} \mathrm{SO}_{4}$ and $1 \mathrm{M} \mathrm{NaOH}$ electrolytes were recorded on a Bruker AVIII HD 400 instrument with $\mathrm{D}_{2} \mathrm{O}$ enclosed in a capillary.

TGA was conducted on a thermogravimetric analyzer Perkin Elmer TGA-7, heating from 30 to $600{ }^{\circ} \mathrm{C}\left(10{ }^{\circ} \mathrm{C} \cdot \mathrm{min}^{-1}\right)$ under $\mathrm{N}_{2}$ flow, and from 30 to $900{ }^{\circ} \mathrm{C}$ under air flow.

Isothermal calorimetry was performed on a VP-ITC (MicroCal Inc.) instrument. A PEG solution $\left(20 \mathrm{mg} \mathrm{mL}^{-1}, 300 \mu \mathrm{L}\right)$ loading in a rotating $(500 \mathrm{rpm})$ syringe was injected into a sample cell with water $(1.4545 \mathrm{~mL})$ or an aqueous suspension containing multiwalled CNTs $(0.05 \mathrm{mg} \mathrm{mL}, 1.4545 \mathrm{~mL})$ in sequential $1.4 \mu \mathrm{L}$ aliquots at a rate of 1 aliquot every 3 min. All measurements were recorded at $25.0^{\circ} \mathrm{C}$.

SEM images were recorded on a Zeiss Merlin instrument operated at $1-3 \mathrm{kV}$ and equipped with an Inlens secondary electron detector. TEM were recorded on a Tecnai Osiris instrument at an activation voltage of $200 \mathrm{kV}$. The EDS mapping image was taken under HAADF-STEM mode. The sample for TEM was prepared by drop-drying the samples from diluted ethanol suspensions onto carbon coated copper grids.

The Brunauer-Emmett-Teller (BET) surface area was calculated from $\mathrm{N}_{2}$ physisorption measurements employing a Quantachrome Autosorb-IQ/MP-XR instrument. 
Samples (ca. $35 \mathrm{mg}$ ) were dried at $120^{\circ} \mathrm{C}$ (temperature reached with a ramp of $2{ }^{\circ} \mathrm{C} \mathrm{min}^{-1}$ ) under vacuum $\left(<10^{-3} \mathrm{mbar}\right)$ for $10 \mathrm{~h}$ and a leak test was performed prior to analysis.

Tensile strength was determined on a Zwicky $5 \mathrm{kN}$ uniaxial testing machine equipped with a $100 \mathrm{~N}$ detector set as a stretching rate of $10 \mathrm{~mm} \mathrm{mim}^{-1}$. Measurements were repeated 6 times. Tape samples $(5 \mathrm{~cm} \times 1 \mathrm{~cm} \times \mathrm{ca} .20 \mu \mathrm{m})$ were used for the tests. Dry CNT-PVC composites and dry and wet CNT-PAN composites were used for the analysis.

Water contact angle measurements were performed at ambient temperature via the sessile-drop method using an optical contact angle meter (EasyDrop/KRUSS, water droplet $=2 \mu \mathrm{L})$.

UV-Vis spectra were recorded on a SpectraMax M5e instrument.

The molecular weight cut-off (MWCO) of the CNT-PAN composite membranes was determined using a homemade cell. The cell is composed of two pieces of stainless steel, and a piece of silicon sealing rubber ( $3 \mathrm{~mm}$ in thickness), all having a window of 25 $\mathrm{mm} \times 35 \mathrm{~mm}$. A piece of the CNT-PAN composite membrane $(45 \mathrm{~mm} \times 55 \mathrm{~mm})$ was sandwiched between the stainless steel and silicon sealing rubber at the front and back windows. An aqueous solution of dextran (10 $\mathrm{mg} \mathrm{mL}^{-1}, 2 \mathrm{~mL}, \mathrm{M}_{\mathrm{w}}=2.5,6,10,20,40,70$, $150,500 \mathrm{kDa}$ ) was slowly injected into the cell under ambient conditions, then the cell was dialyzed in deionized water $(200 \mathrm{~mL})$ under ambient condition three times for 6 hours. The dextran solution after dialysis was collected and dried, and the retained dextran was determined by weighing. Commercial semi-permeable membrane with $10 \mathrm{kDa}$ MWCO was used as a control.

Electrical tests were conducted on a Bio Logic SP300 potential station using beltshaped carbon paper (AvCarb MGL280) as a comparison material. The samples were $5 \mathrm{~cm}$ $\times 1 \mathrm{~cm}$ in size. All electrochemical measurements were carried out on a Bio Logic SP300 potential station. The CNT-PAN and CNT-PAN-Pt composite membrane electrodes and belt-shaped carbon paper were used as working electrodes, Pt foil was used as the counter electrode, $\mathrm{Ag} / \mathrm{AgCl}$ electrode with a saturated $\mathrm{KCl}$ filling solution was used as the reference electrode. Potential versus RHE was calculated using $\mathrm{E}_{\mathrm{vs} \cdot \mathrm{RHE}}=\mathrm{E}_{\mathrm{vs} . \mathrm{Ag} / \mathrm{AgCl}}+0.197 \mathrm{~V}+$ $0.0592 \mathrm{~V} \times \mathrm{pH}$. The $\mathrm{pH}$ values of the electrolytes were measured with a $\mathrm{pH}$ meter. The $\mathrm{pH}$ values of $\mathrm{N}_{2}$ saturated $0.5 \mathrm{M} \mathrm{H}_{2} \mathrm{SO}_{4}$ and $1 \mathrm{M} \mathrm{NaOH}$ electrolytes used in this work were 
0.25 and 13.57, respectively. 20 cycles of CV sweeps were conducted before the collection of linear sweep voltammetry (LSV) curves of CNT-PAN-Pt, which were collected at a scanning rate of $1 \mathrm{mV} \mathrm{s}^{-1}$. Automatic $i R$ compensation (85\%) was used. 

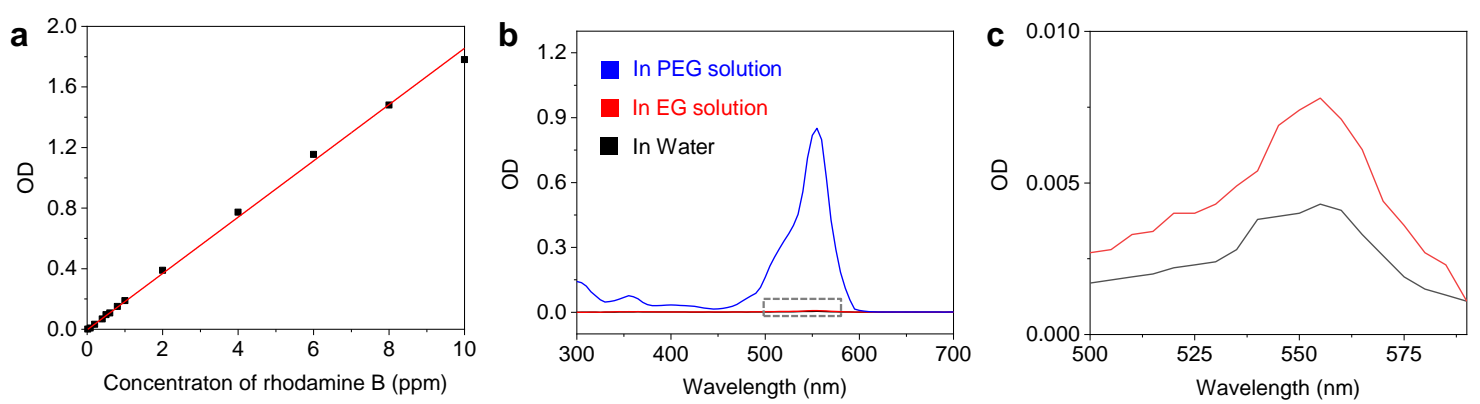

Figure S1. Determination of rhodamine B displacement from doped CNTs. (a) The calibration curve of rhodamine $\mathrm{B}$ in the concentration range $0.02-10 \mathrm{ppm}$. (b) Corresponding UV-vis spectra of released rhodamine B in water (black), aqueous EG solution (red) and aqueous PEG solution (blue). (c) The enlarged area in the region 500 $590 \mathrm{~nm}$ from the corresponding spectra in (b). 


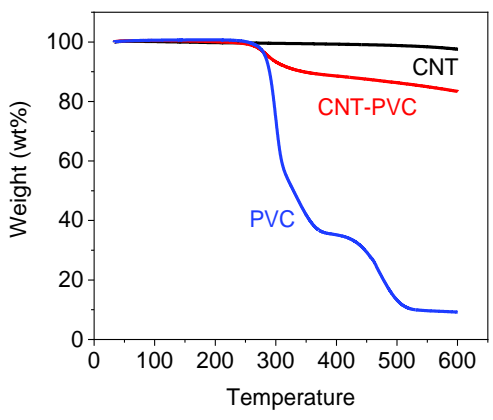

Figure S2. TGA of the CNTs (black), CNT-PVC composite (red) and PVC (blue) recorded under $\mathrm{N}_{2}$. 

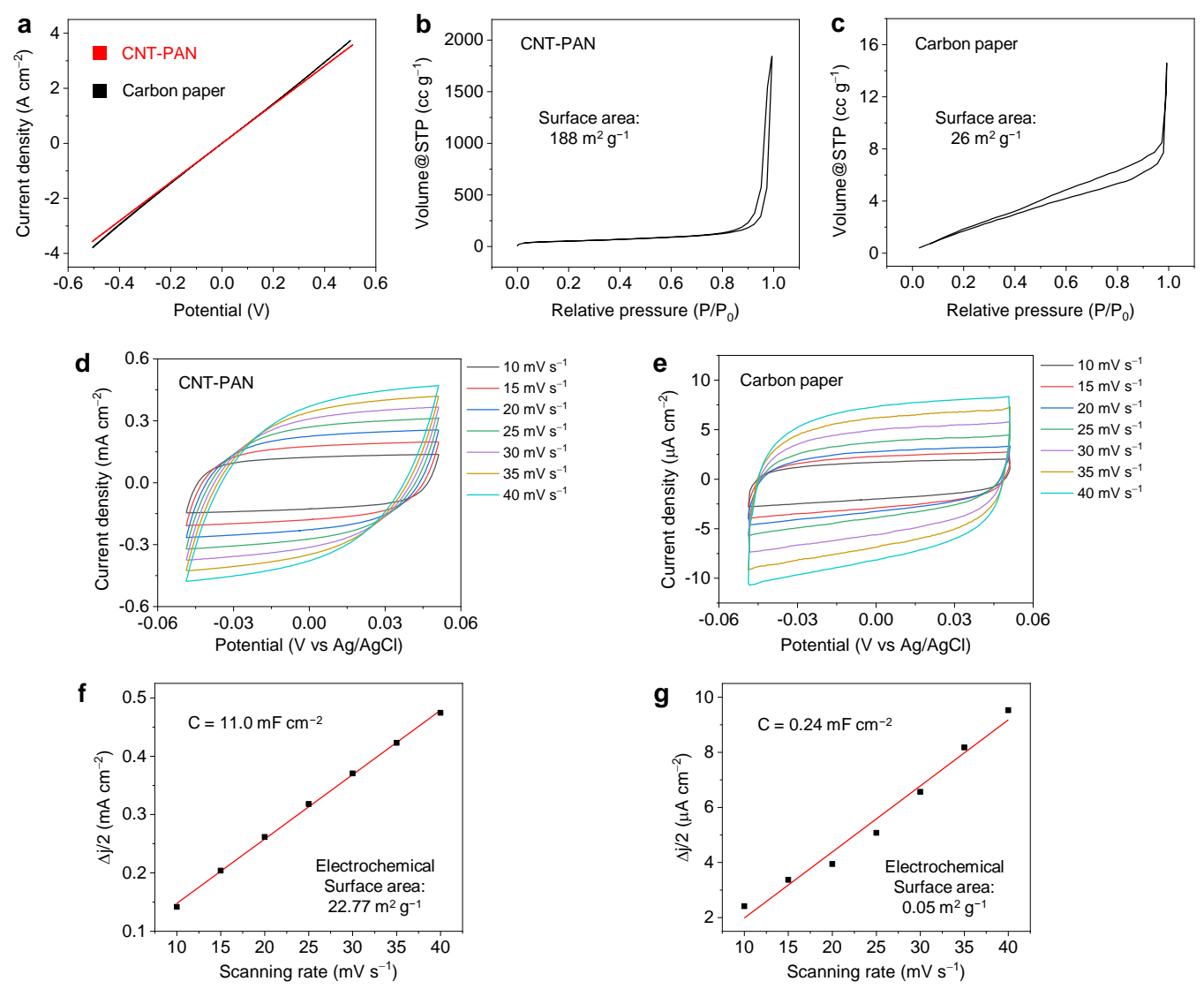

Figure S3. Comparison of the conductivity, surface area and electrochemical surface area of the CNT-PAN composite membrane with carbon paper. (a) Current density of the CNTPAN composite membrane and carbon paper in the potential range $-0.5-0.5 \mathrm{~V}$. BET isothermal adsorption of (b) the CNT-PAN composite membrane and (c) carbon paper. CV curves of (d) the CNT-PAN composite membrane and (e) carbon paper in $0.5 \mathrm{M} \mathrm{Na}_{2} \mathrm{SO}_{4}$ electrolyte at a scan rate of $10-40 \mathrm{mV} \mathrm{s}^{-1}$. Corresponding linear fitting of the difference of current densities between anodic and cathodic scans with the scan rates to determine the double layer capacitance (C) and electrochemical surface area* of (f) the CNT-PAN composite membrane and (g) carbon paper.

* The electrochemical surface area was calculated from the double layer capacitance, assuming the double layer capacitance per $\mathrm{cm}^{2}$ of the electrochemical surface area of the materials is identical to that of graphene, namely $21 \mu \mathrm{F} \mathrm{cm}{ }^{-2} \cdot{ }^{37}$ The electrochemical surface area on the CNT-PAN composite membrane and carbon paper are 0.0524 and $0.0011 \mathrm{~m}^{2}$ $\mathrm{cm}^{-2}$, respectively. The corresponding mass of the CNT-PAN composite membrane and carbon paper were 2.3 and $23 \mathrm{mg} \mathrm{cm}^{-2}$, respectively. Thus, the mass normalized electrochemical surface area of the CNT-PAN composite membrane and carbon paper is 22.77 and $0.05 \mathrm{~m}^{2} \mathrm{~g}^{-1}$, respectively. 

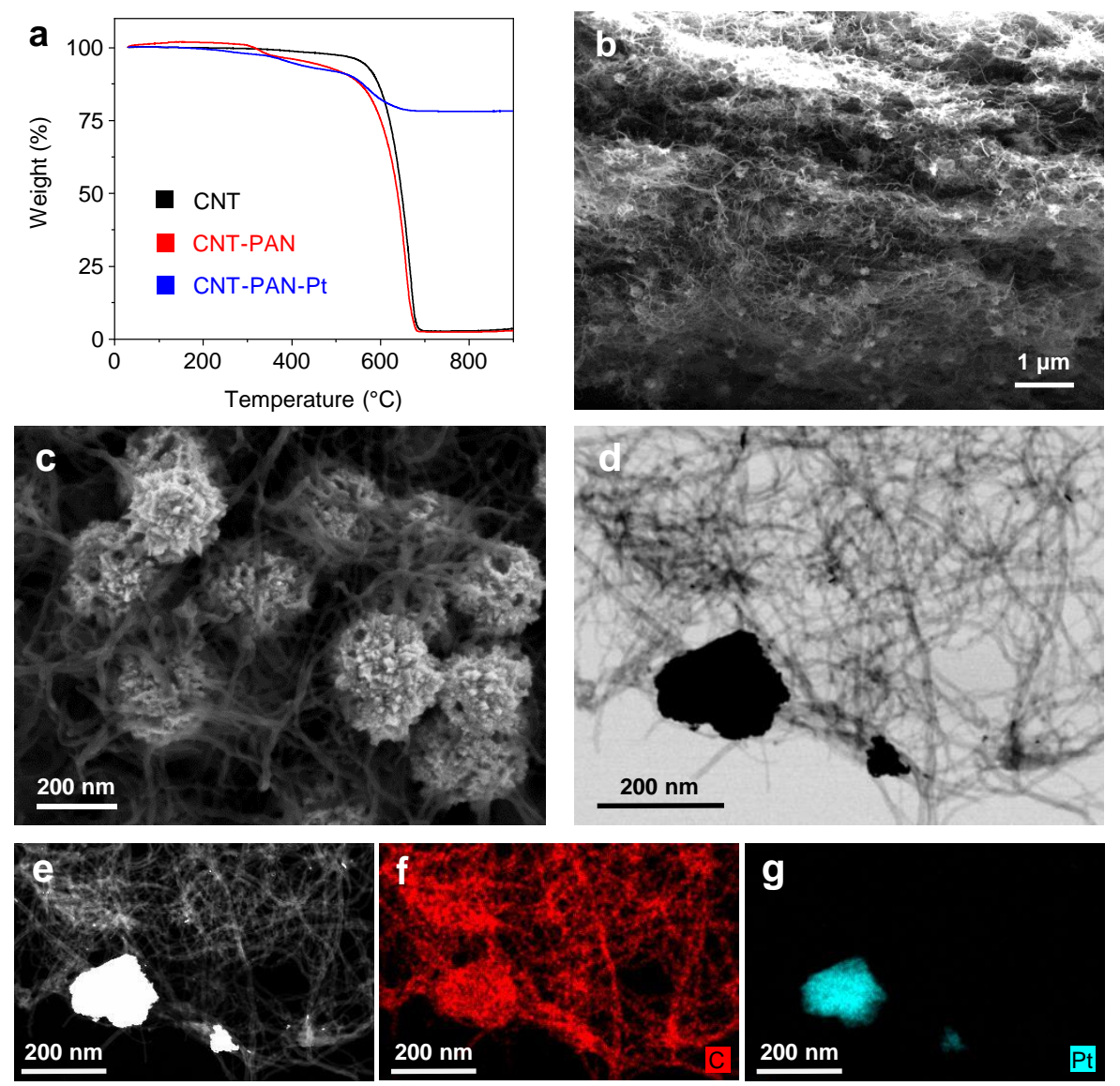

Figure S4. Characterization of CNT-PAN-Pt composite membrane electrode. (a) TGA of the CNTs (black), CNT-PAN composite membrane (red) and CNT-PAN-Pt composite membrane electrode (blue) under air. (b) SEM of inner section (16 18 $\mu \mathrm{m}$ in depth) of the CNT-PAN-Pt composite membrane electrode. (c) Enlarged SEM image of the CNT-PANPt electrode. (d) Bright field TEM image of the CNT-PAN-Pt electrode. (e) HAADF image of the CNT-PAN-Pt electrode. EDS images of (f) carbon and (g) platinum of the CNTPAN-Pt electrode. 

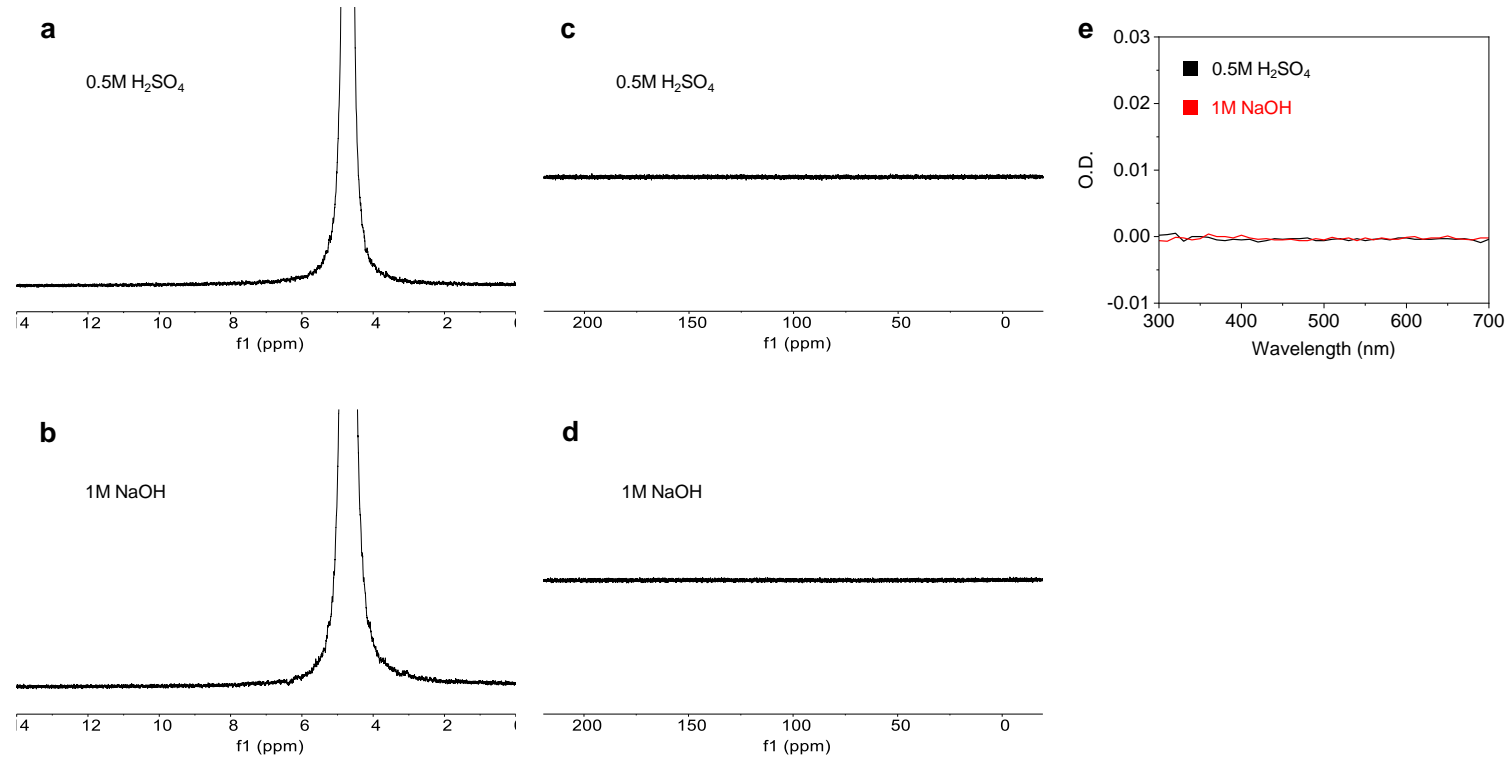

Figure S5. NMR and UV-vis spectroscopic analysis of the electrolyte solution to reveal the long-term stability of the CNT-PAN-Pt composite membrane electrode in harsh $\mathrm{pH}$ conditions. The ${ }^{1} \mathrm{H}$ NMR spectrum of (a) $0.5 \mathrm{M} \mathrm{H}_{2} \mathrm{SO}_{4}$ and (b) $1 \mathrm{M} \mathrm{NaOH}$ electrolyte solutions, and the ${ }^{13} \mathrm{C}$ NMR spectrum of (c) $0.5 \mathrm{M} \mathrm{H}_{2} \mathrm{SO}_{4}$ and (d) $1 \mathrm{M} \mathrm{NaOH}$ electrolyte solutions after 36 hours chronoamperometry testing of the CNT-PAN-Pt composite membrane electrode at a current density at $20-25 \mathrm{~mA} \mathrm{~cm}^{-2}$. (e) The UV-vis spectrum of the corresponding $0.5 \mathrm{M} \mathrm{H}_{2} \mathrm{SO}_{4}$ (black) and $1 \mathrm{M} \mathrm{NaOH}$ (red) electrolyte solutions. 
NMR dataset for thermodynamic calculation ${ }^{38}$

NMR dataset for Table 1, entry 1:
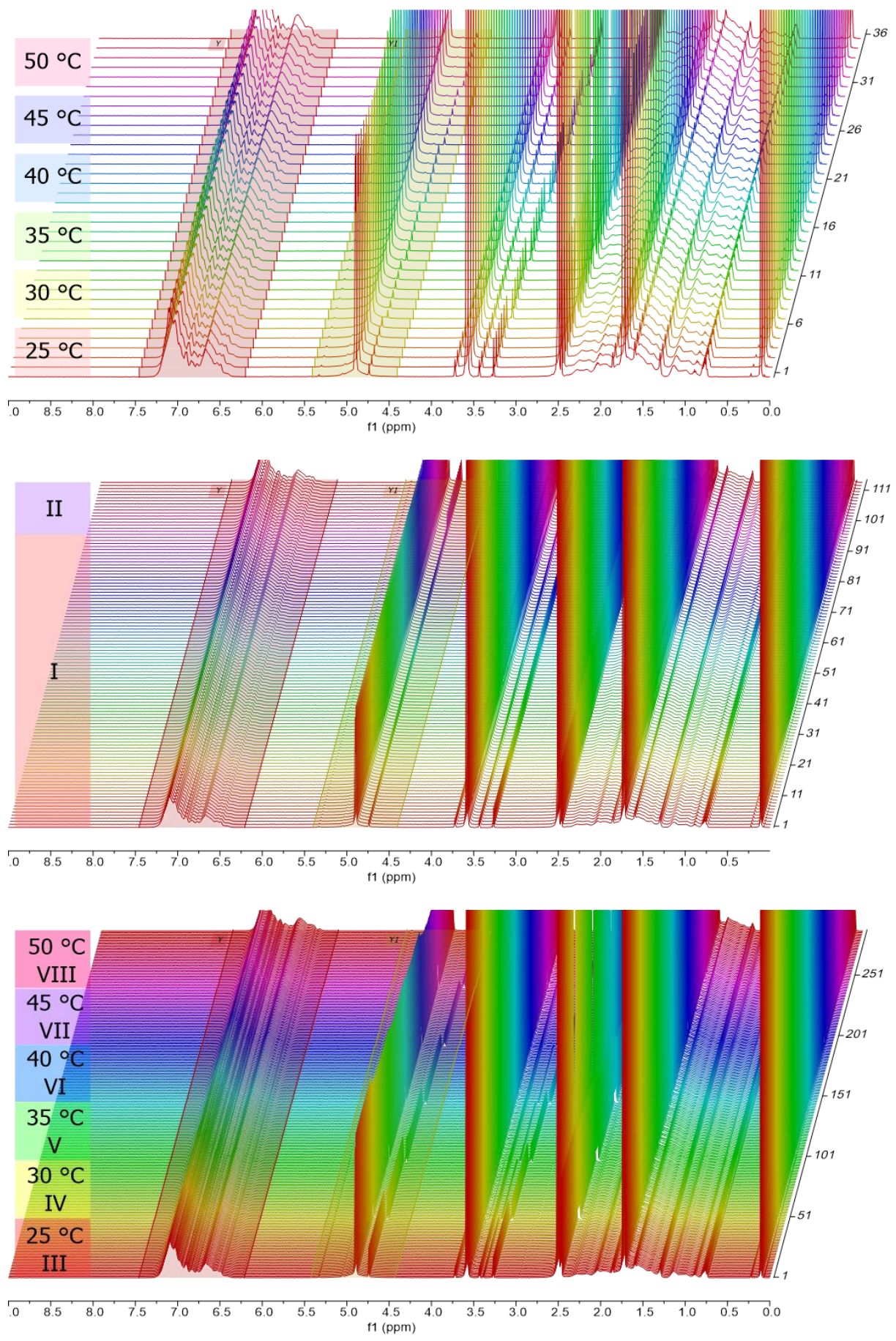
NMR data set for Table 1, entry 2:
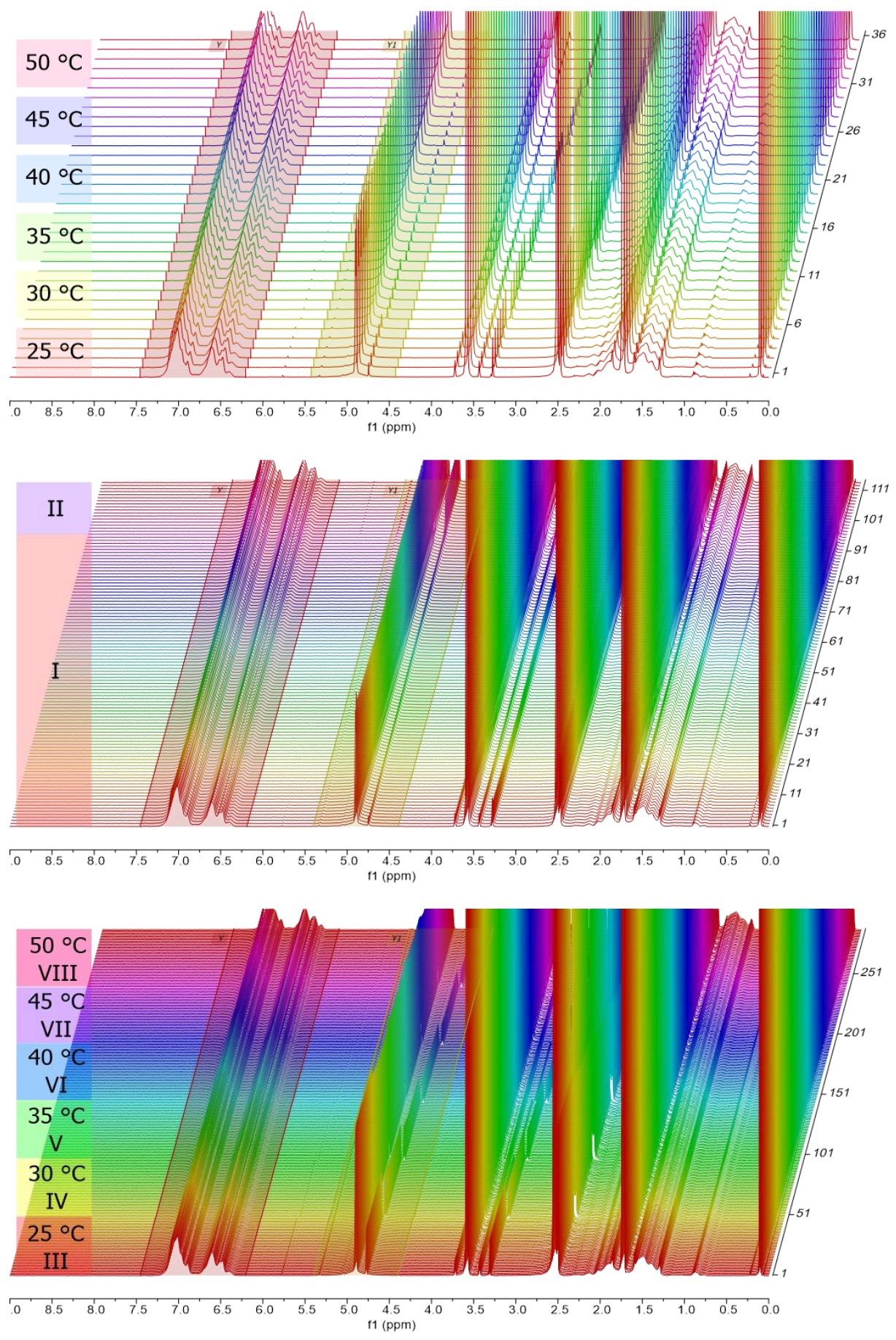
NMR data set for Table 1, entry 3 :
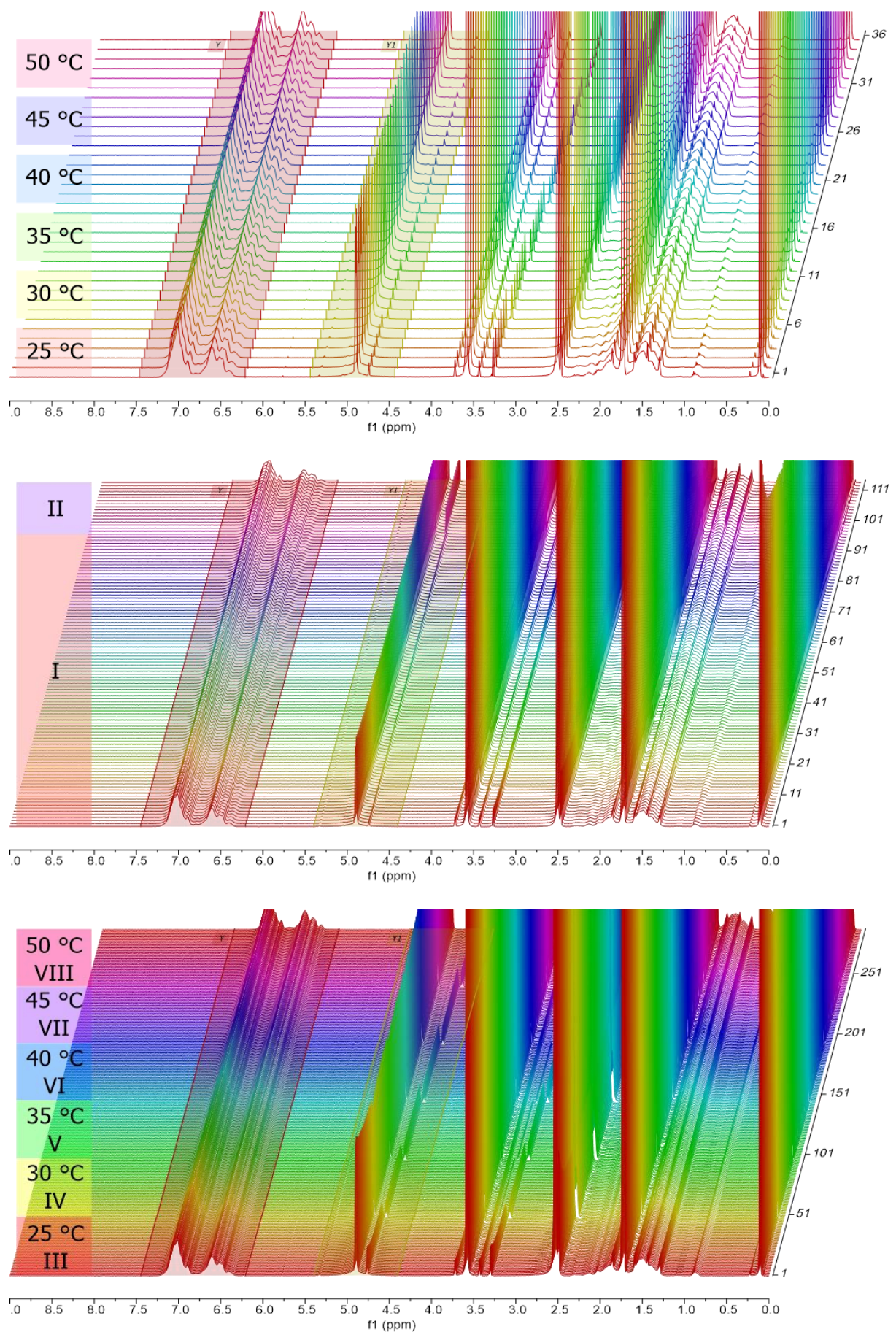
NMR data set for Table 1, entry 4:
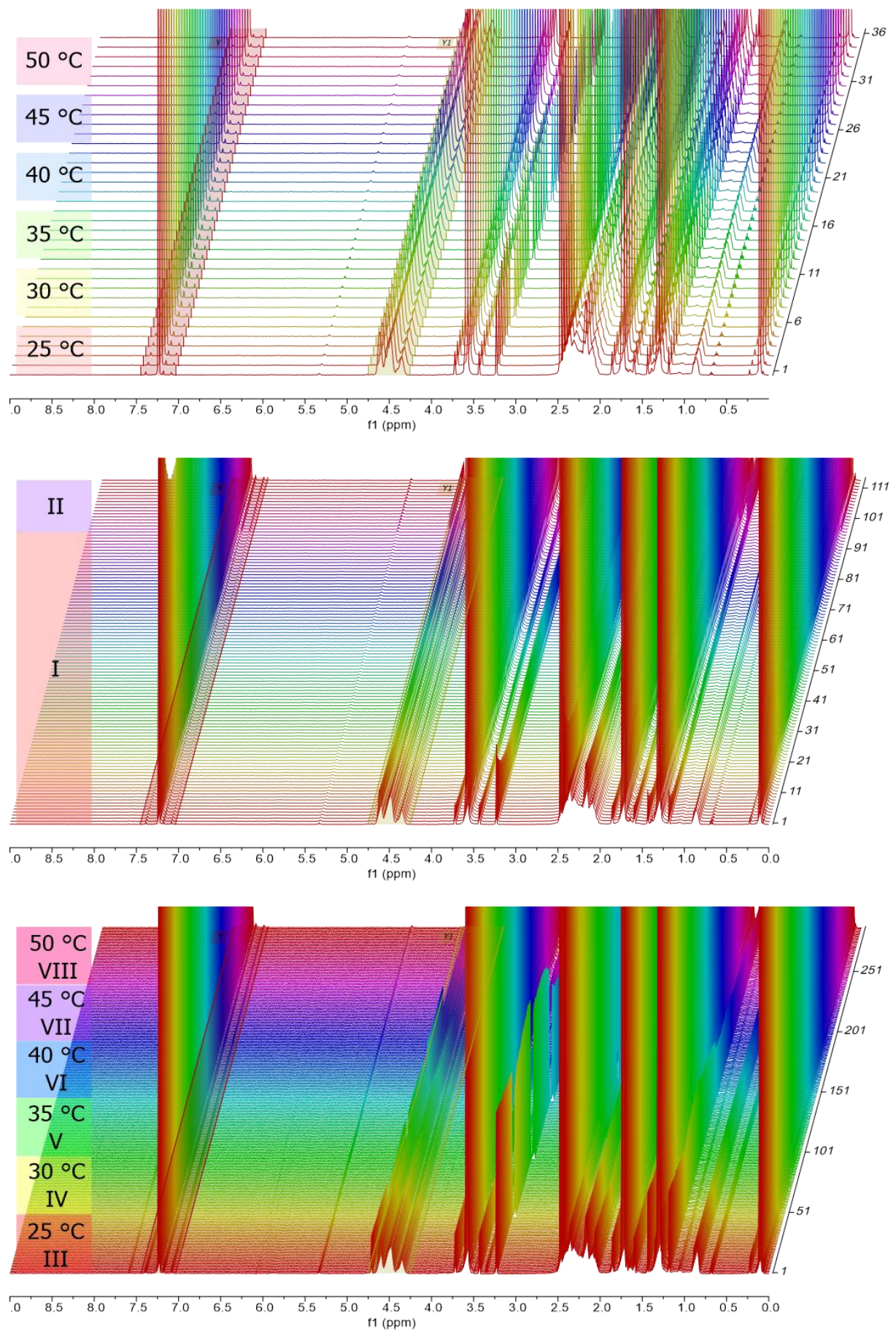
NMR data set for Table 1, entry 5:
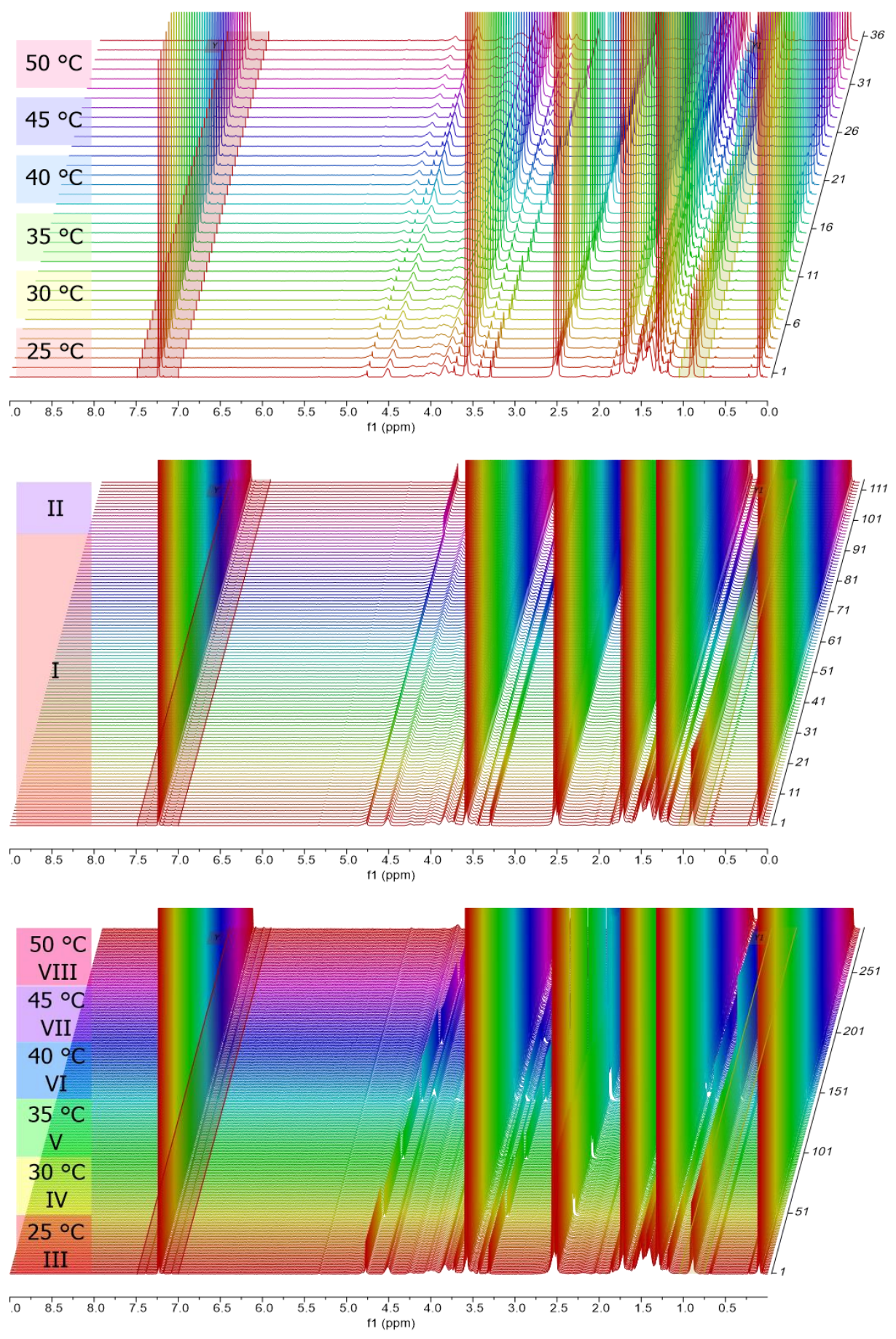
NMR data set for Table 1, entry 6:
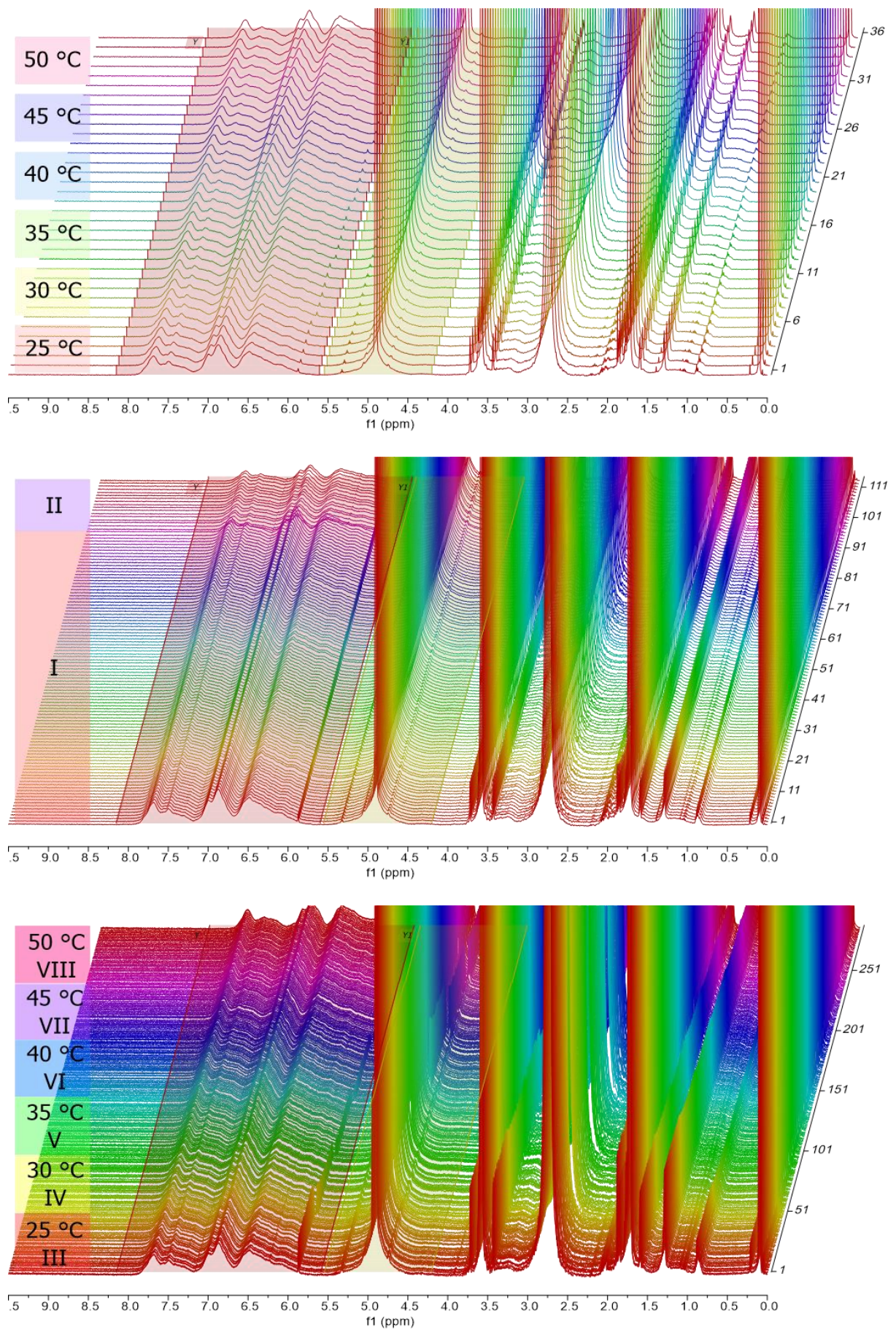
NMR data set for Table 1, entry 7 :
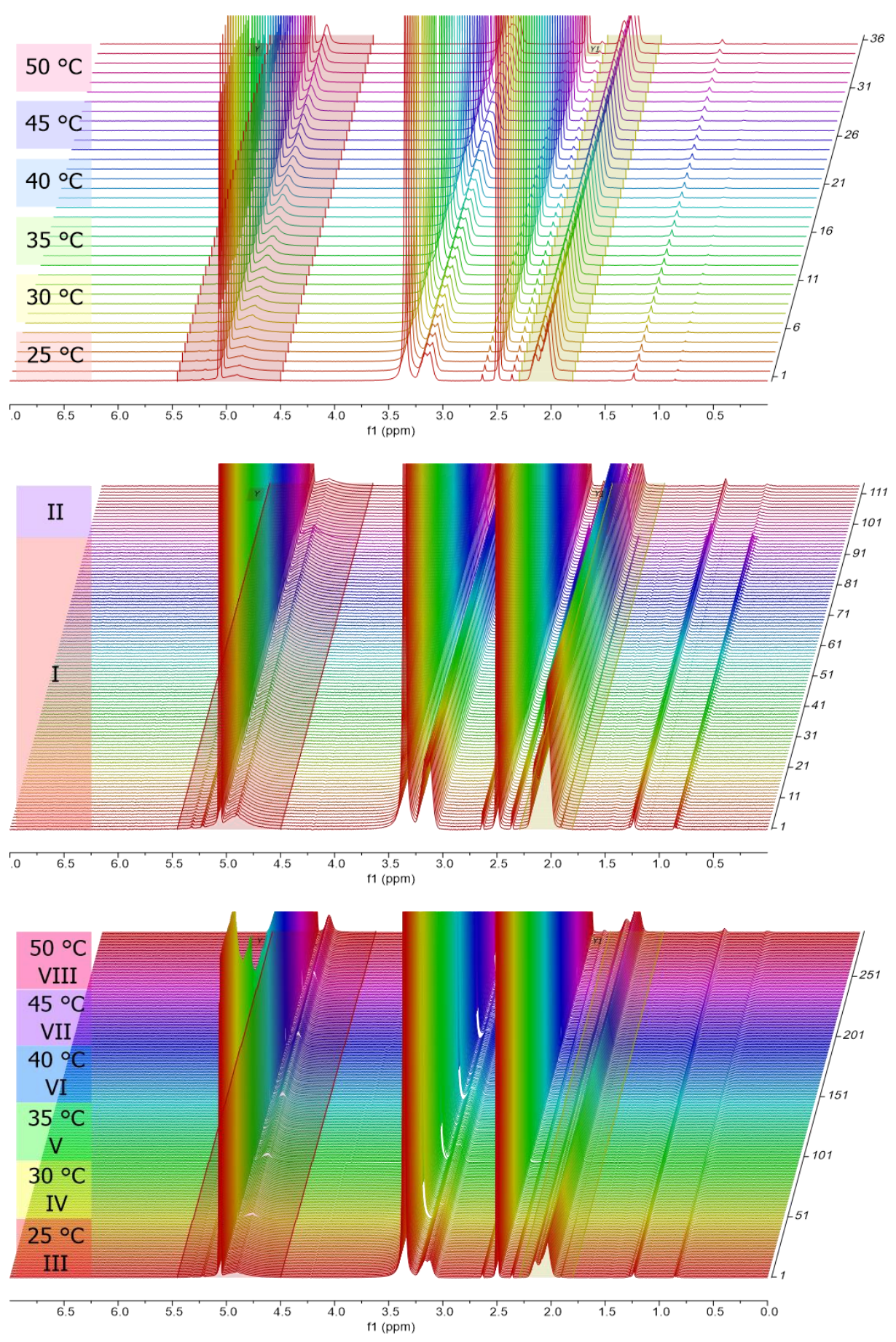
NMR data set for Table 1, entry 8:
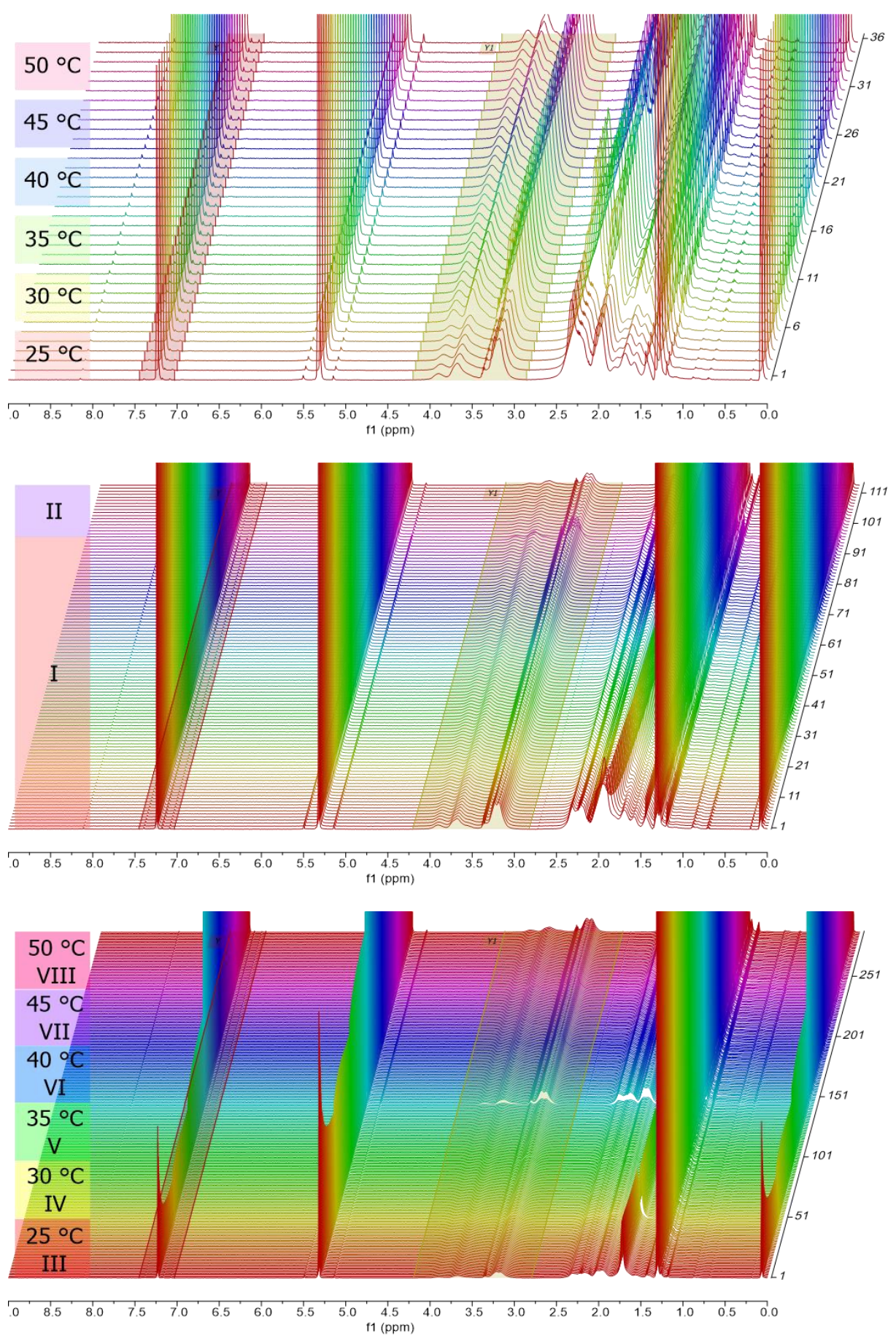
NMR data set for Table 1, entry 9:
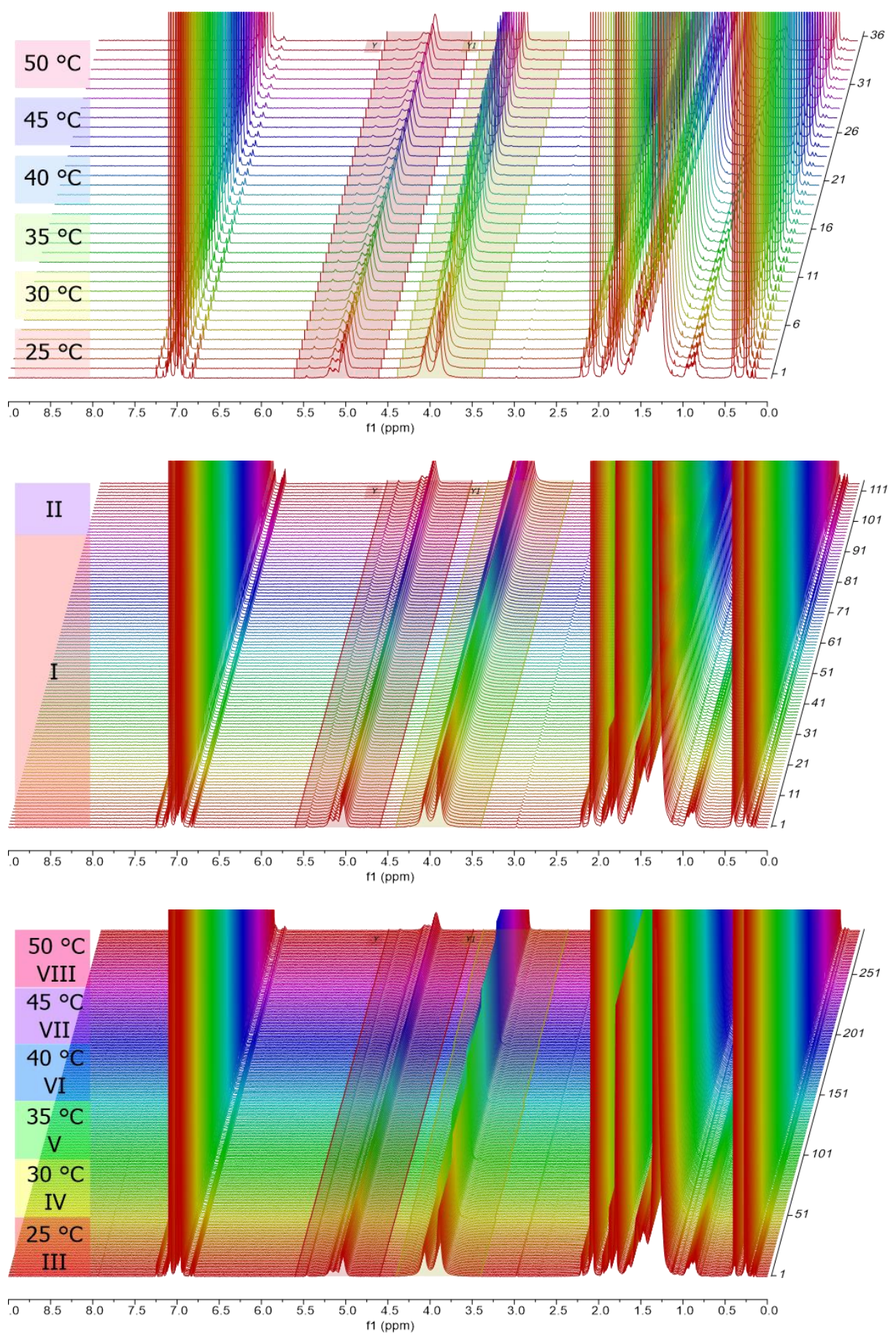
NMR data set for Table 1, entry 10:
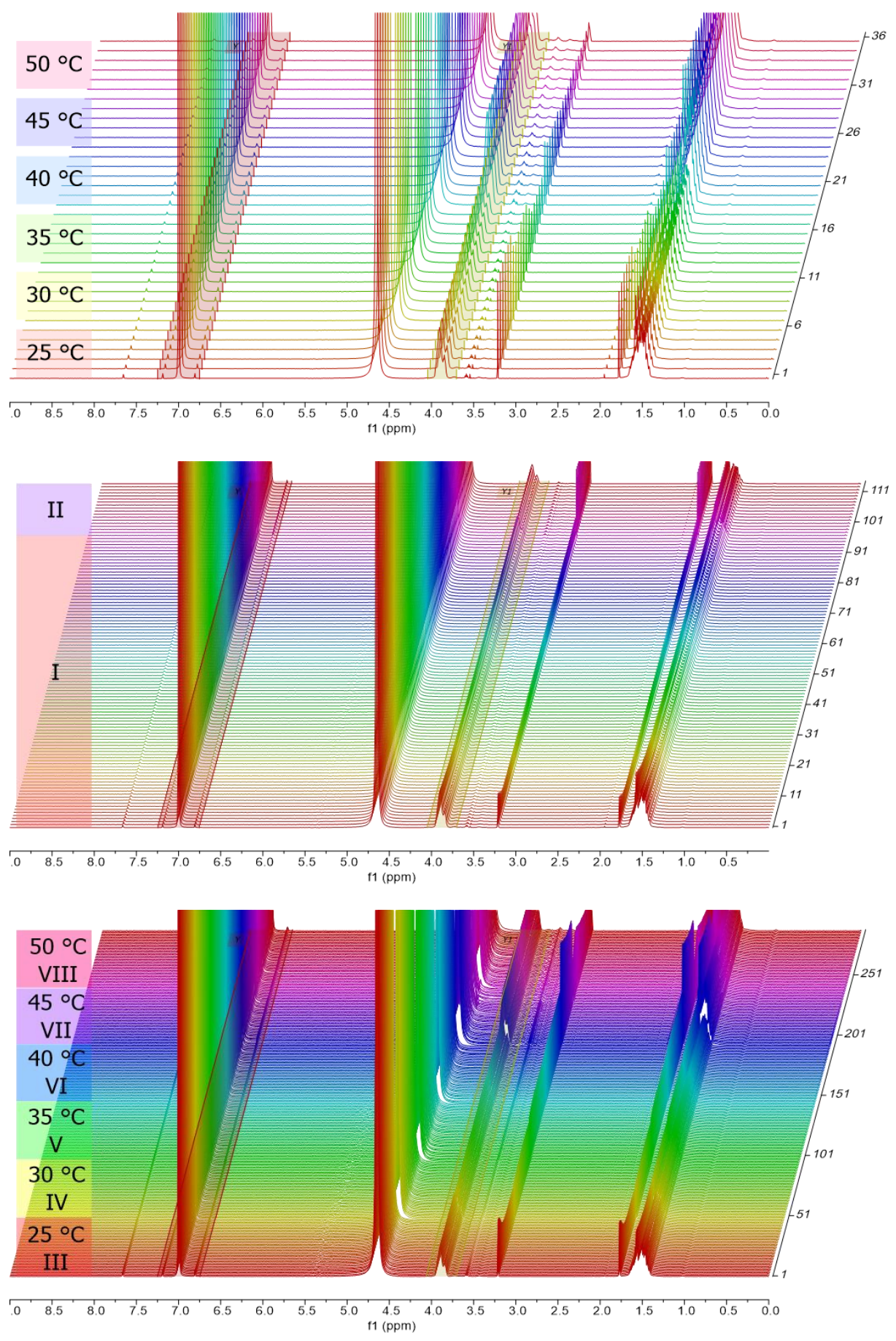
NMR data set for Table 1, entry 11:
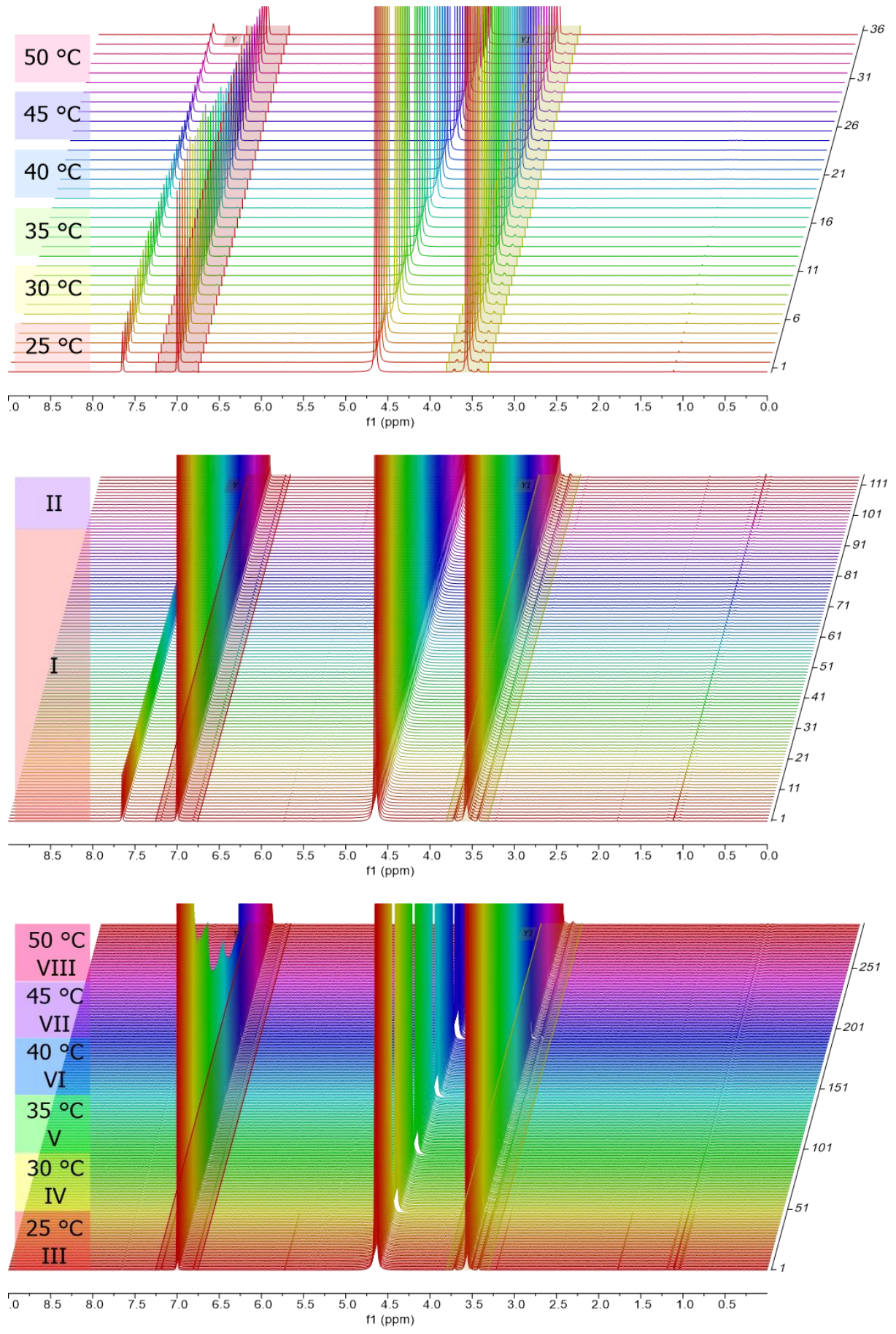
NMR data set for Table 1, entry 12:
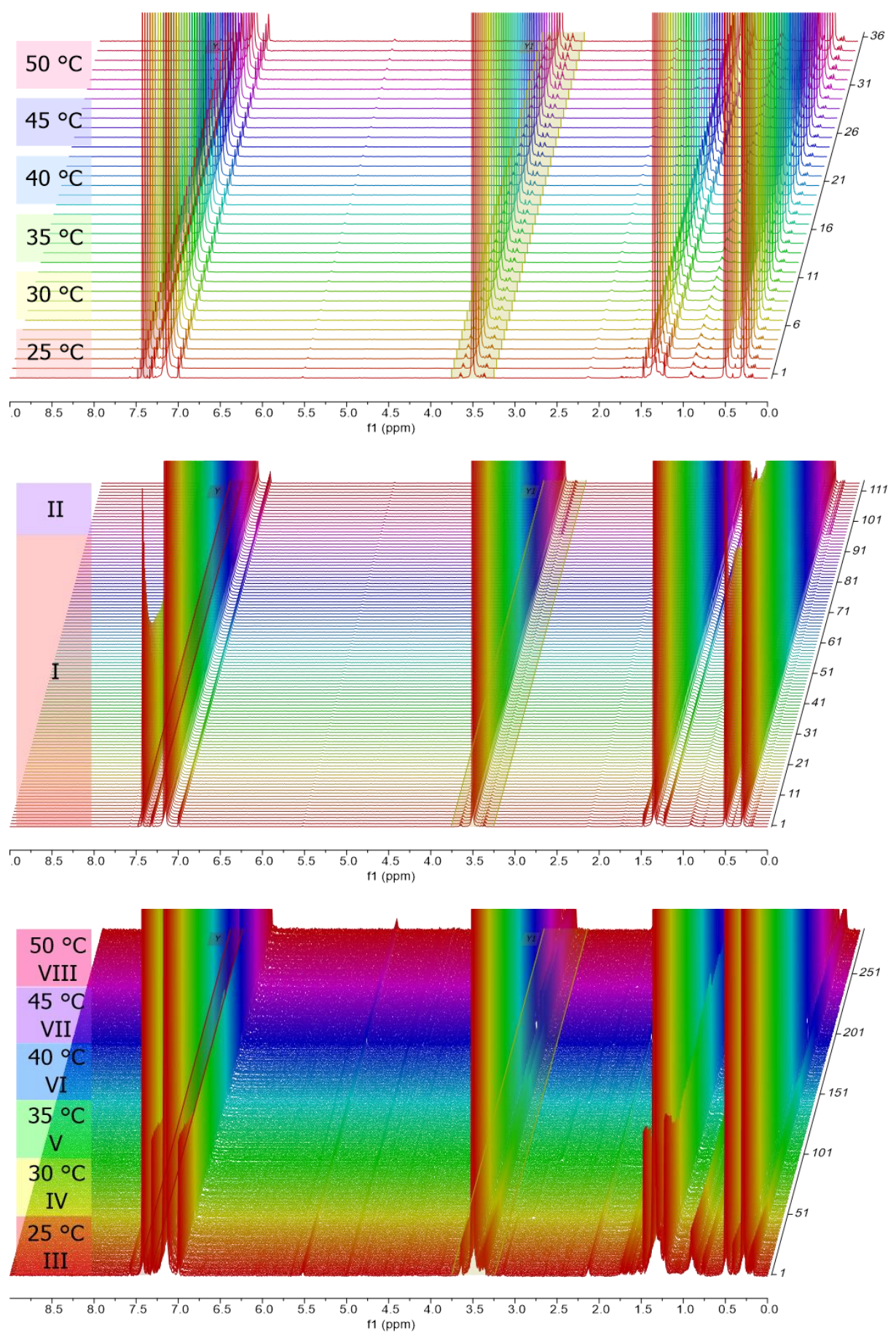
NMR data set for Table 1, entry 13:
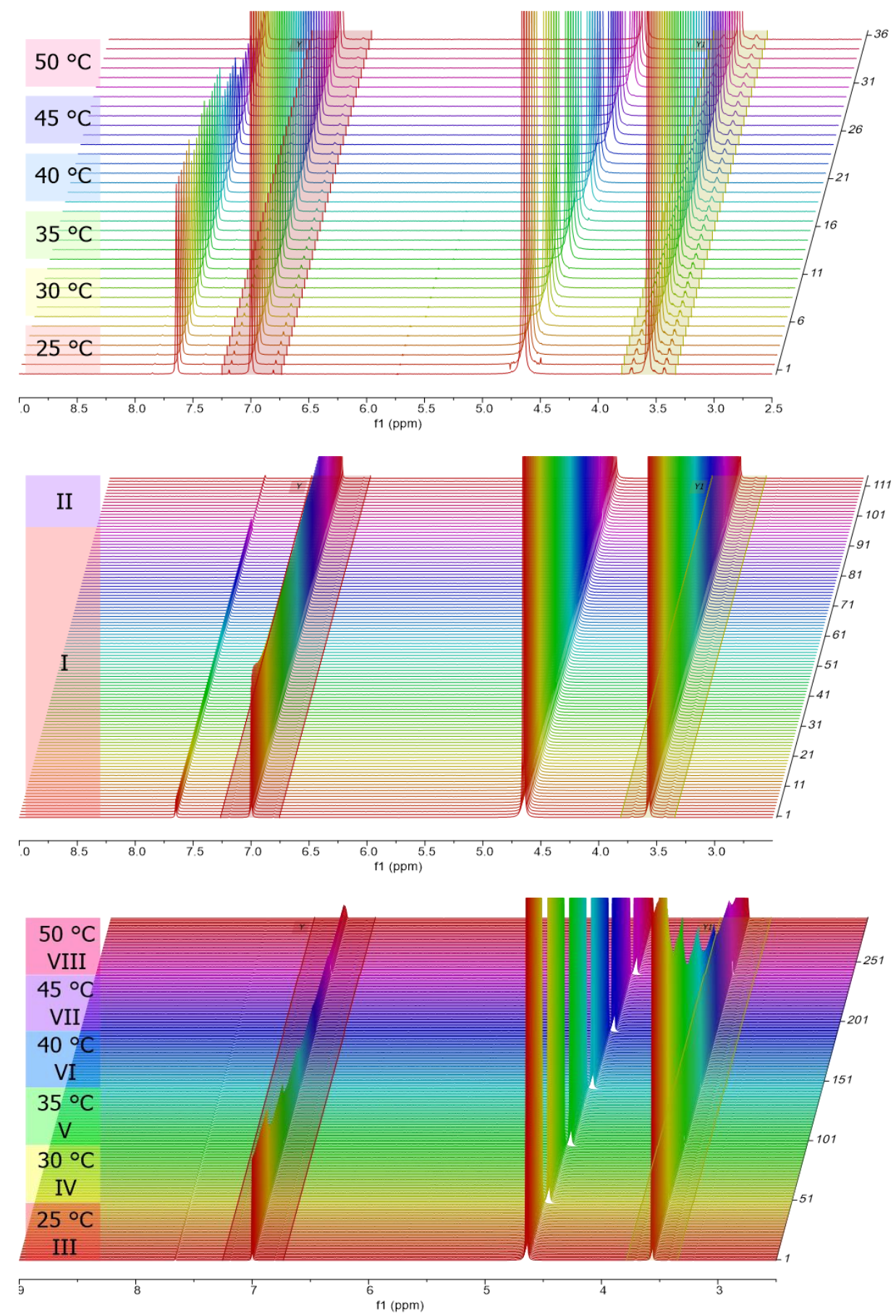
NMR data set for Table 1, entry 14:
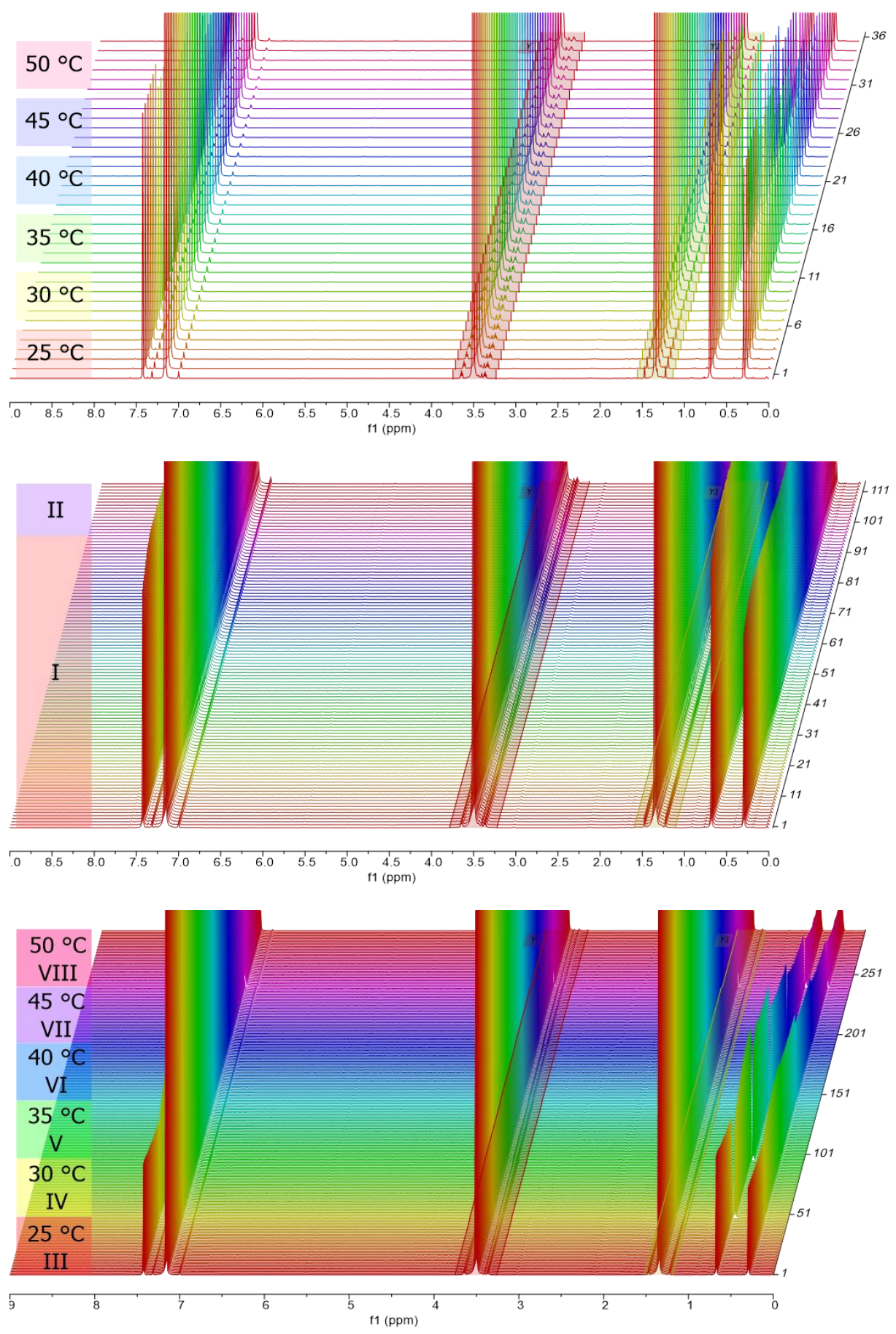
NMR data set for Table 1, entry 15:
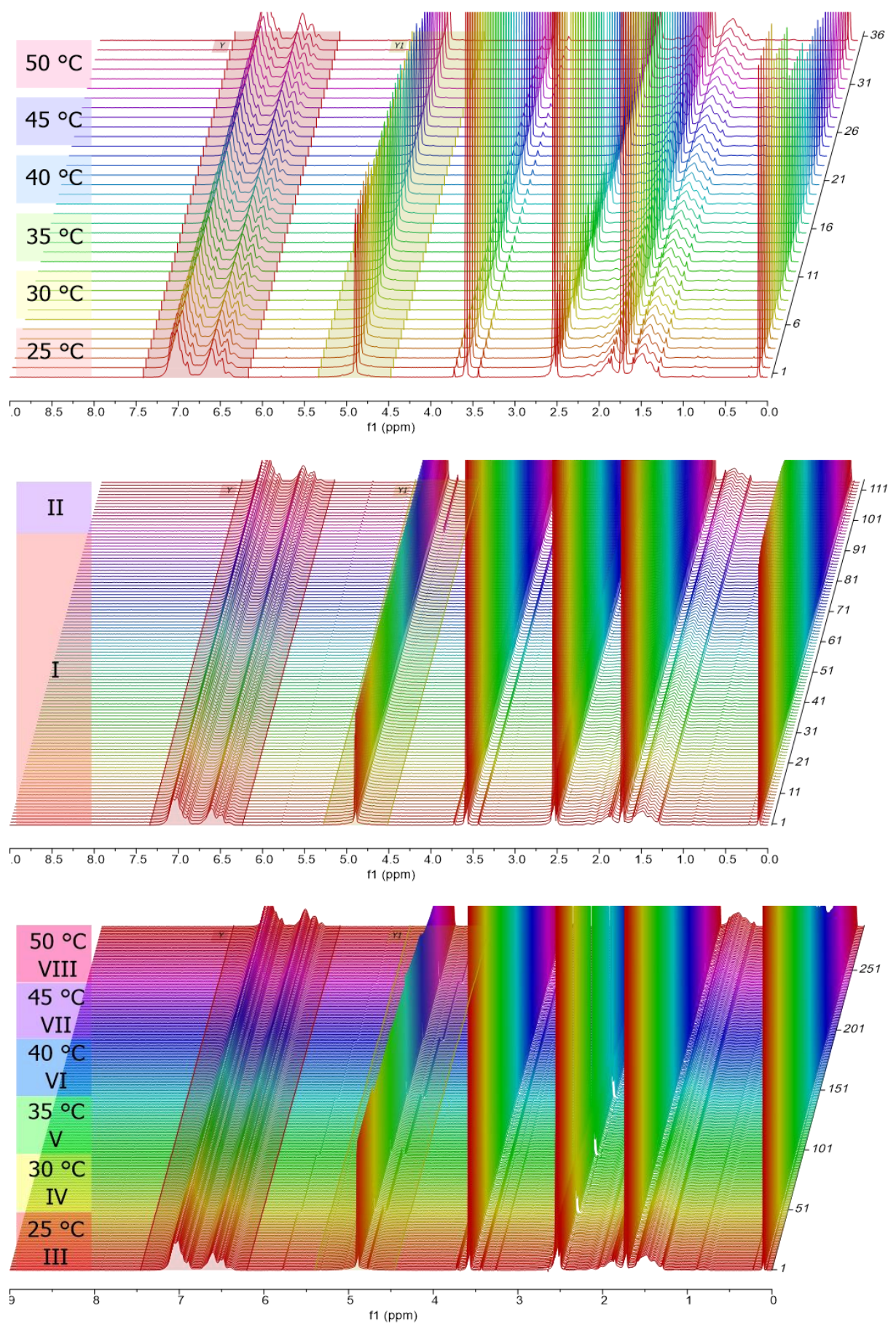


\section{References}

36. Peng, Y., Liu, H. Effects of oxidation by hydrogen peroxide on the structures of multiwalled carbon nanotubes. Ind. Eng. Chem. Res. 45, 6483-6488 (2006).

37. Chen, J., Li, C., Shi, G. Graphene materials for electrochemical capacitors. J. Phys. Chem. Lett. 4, 1244-1253 (2013).

38. The corresponding xlsx profile is in Zenodo server, DOI: $10.5281 /$ zenodo.3888433 